\title{
Existe um efeito negativo duplo sobre os salários das mulheres migrantes nas regiões brasileiras? Uma abordagem não paramétrica
}

\author{
Maria Adreciana Silva de Aguiar \\ João Mário Santos de França**
}

Este artigo busca verificar se existe um efeito negativo duplo sobre os salários das mulheres migrantes (não naturais e de retorno) nas regiões brasileiras. Para captar o diferencial salarial, empregou-se o método não paramétrico de Ñopo (2008) aplicado aos dados obtidos a partir da Pesquisa Nacional por Amostra de Domicílios (PNAD) de 2005 e 2015. Os resultados mostraram que apenas a mulher migrante não natural na região Sudeste sofre de dupla desvantagem no mercado de trabalho. A primeira desigualdade salarial refere-se à questão de gênero e ocorre também nas demais regiões brasileiras. A segunda diferença no salário deve-se à condição de migrante não natural da região Sudeste. Para as demais regiões, as mulheres migrantes (não naturais e de retorno) possuem uma vantagem salarial em relação às não migrantes.

Palavras-chave: Mulheres migrantes. Desvantagem salarial. Decomposição de Ñopo.

\footnotetext{
*Universidade Federal do Ceará (UFC), Fortaleza-CE, Brasil (adreciane@gmail.com; https://orcid.org/0000-0003-1163-9734). ${ }^{\star *}$ Universidade Federal do Ceará (UFC), Fortaleza-CE, Brasil (joao.franca@ufc.br; https://orcid.org/0000-0001-6805-808X).
} 


\section{Introdução}

Apesar da maior participação da mulher no mercado de trabalho nos últimos anos, a força de trabalho feminina ainda enfrenta barreiras, como, por exemplo, a recorrente discrepância salarial existente entre homens e mulheres. A partir de dados da Pesquisa Nacional por Amostra de Domicílios (PNAD) de 2015, Paschoalino, Plassa e Santos (2017) sugerem que ainda há uma diferença salarial no Brasil segundo gênero de $13 \%$, que favorece os homens.

Além da maior participação na força de trabalho, as mulheres também estão mais presentes nos estudos sobre os fluxos migratórios. Até o início dos anos de 1970, os estudos sobre migração não levavam em conta as diferenças de gênero, raça e etnia.

Por muito tempo as experiências das mulheres migrantes não foram incorporadas na literatura, ficando estas em lugar secundário nas questões migratórias. Isso estava relacionado ao fato de os homens serem vistos como mais aptos aos riscos da migração e as mulheres estarem apenas engajadas com os serviços domésticos. As mulheres migrantes não ocupavam posição favorável no mercado de trabalho, seja pela segregação dos postos de trabalho, seja pela discriminação salarial sofrida por elas, deixando-as invisíveis nos estudos sobre migração (ASSIS, 2007).

As motivações que levam um indivíduo a migrar podem diferir entre homens e mulheres. A decisão de migrar para os homens está vinculada à procura por trabalho, enquanto para as mulheres sempre esteve mais relacionada à decisão de acompanhar a família (ASSIS; ALVES, 2014; OLIVEIRA; JANNUZZI, 2005).

As mulheres geralmente ingressavam no mercado de trabalho no local de destino para complementar a renda familiar, tendo em muitas situações um salário reserva menor do que o do cônjuge (ASSIS; ALVES, 2014; AGUIAR; FRANÇA, 2017). Autores como Mincer (1978) e Borjas (2004) sugerem que as mulheres migrantes tendem a ser tied movers, ou seja, se moviam com o cônjuge mesmo que sua perspectiva de emprego piorasse na região de destino.

No entanto, os fluxos migratórios contemporâneos mostram que as mulheres deixam a imagem de que se deslocam principalmente por razões familiares, como acompanhantes do cônjuge ou do chefe do domicílio (pais ou parentes), e começam a migrar sozinhas e por questões econômicas. Alguns estudos apresentam indícios dessa mudança, tais como Assis (2007), Neves et al. (2016) e Aguiar e França (2017). ${ }^{1}$

Vários autores ${ }^{2}$ que realizaram estudos internacionais com foco exclusivo nas mulheres migrantes apontam que elas sofrem dupla discriminação no mercado de trabalho. A primeira está relacionada a um ambiente de oportunidade desigual no mercado de trabalho com

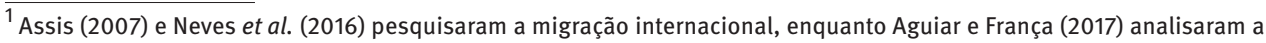
migração de retorno ao Nordeste brasileiro.

${ }^{2}$ Autores como Shamsuddin (1998), Husted et al. (2000), Hayfron (2002), Le e Miller (2010) e Nicodemo e Ramos (2012) realizaram o estudo sobre dupla discriminação das mulheres migrantes para Canadá, Dinamarca, Noruega, EUA e Espanha, respectivamente.
} 
relação ao status de migrante. E a segunda pelo fato de as mulheres terem mais dificuldade de inserção na força de trabalho do que os homens, precisando superar a discriminação de gênero. De acordo com esses estudos, as mulheres migrantes terão mais dificuldades de integração no mercado de trabalho do que aquelas nativas e os homens migrantes.

A literatura nacional sobre migração tem dado atenção especial para a análise da diferença salarial entre migrantes e não migrantes. ${ }^{3}$ Geralmente estes trabalhos mostram que essa diferença salarial tende a diminuir quanto mais tempo o migrante permanece no local de destino.

Diante do que foi exposto, o presente artigo tem como objetivo quantificar os diferenciais de salários no mercado de trabalho nas regiões brasileiras, considerando os critérios de status de migrante (migrante não natural e migrante de retorno) e o gênero. Além disso, compara-se o comportamento dos diferenciais segundo sexo e condição de migração, entre 2005 e 2015.

Para tanto, nos dados obtidos a partir das PNADs de 2005 e 2015, aplicou-se o método não paramétrico proposto por Ñopo (2008). Este método é uma alternativa à decomposição de Oaxaca-Blinder (1973) e decompõe em quatro termos o diferencial total de salários, destacando as diferenças nos suportes das distribuições. Segundo Ñopo (2008), a decomposição de Oaxaca-Blinder superestima o componente do diferencial atribuído às características não observáveis.

Portanto, o avanço deste estudo relaciona-se com o foco exclusivo nas mulheres migrantes e na metodologia ainda não utilizada em estudos nacionais que abordam a diferença salarial segundo condição de migração e gênero.

A seguir apresenta-se um levantamento da revisão de literatura sobre diferenciais de salários para as mulheres migrantes. Posteriormente aborda-se a base de dados, além da estratégia empírica, e são discutidos os resultados. Por fim, são tecidas as considerações finais.

\section{Referencial teórico}

Diversos estudos nacionais abordam a questão da diferença salarial devido ao gênero (GIUBERTI; MENEZES-FILHO, 2005; MADALOZZO, 2010; PASCHOALINO; PLASSA; SANTOS, 2017) e vários outros a partir do status de migrante (BATISTA; CACCIAMALI, 2009; ASSIS; ALVES, 2014; AGUIAR; SOUSA; RODRIGUES, 2018).

Segundo Peres e Baeninger (2012), os estudos sobre migração com foco nas mulheres trouxeram à tona os diferenciais salariais e as diferentes decisões de migração e de inserção no mercado de trabalho por sexo antes ignorados pelos artigos. De acordo com vários estudos da literatura internacional, as mulheres imigrantes ganham menos do que as nativas no mercado de trabalho. Uma das explicações desse hiato salarial pode ser dada

\footnotetext{
3 Por exemplo, os estudos de Gama e Hermeto (2017), para Minas Gerais, Lima et al. (2019), para a região do Matopiba (Maranhão, Tocantins, Piauí e Bahia), Batista e Cacciamali (2009), Assis e Alves (2014) e Souza e Silva Filho (2020), para o Brasil, analisaram os diferenciais salariais entre migrantes e não migrantes.
} 
pelo capital humano ou pela discriminação étnica (LE; MILLER, 2008; NICODEMO; RAMOS, 2012; FRIDSÉN; SJÖLANDER, 2018).

Algumas teorias buscam explicar essas diferenças salariais entre dois grupos de trabalhadores. Por exemplo, a teoria da discriminação sugere que o diferencial de salários ocorreria em função das características não produtivas dos trabalhadores, tais como sexo, cor e região de origem (BECKER, 1957).

A teoria da segmentação teria como fonte de discriminação a falta de competição devido às estruturas sociais e aos arranjos institucionais, sendo o mercado de trabalho dividido em primário e secundário (AIGNER; CAIN, 1977). Os teóricos da segmentação sugerem que os migrantes estariam mais inseridos em empregos com baixos salários, alta rotatividade, baixa qualificação e pouca possibilidade de ascensão. Esse mercado, chamado de secundário, seria ocupado principalmente por migrantes, mulheres e jovens (SASAKI; ASSIS, 2000).

Já a abordagem do capital humano sugere que o retorno econômico associado à migração depende, além das características observadas dos indivíduos, dos atributos não observados. Segundo Chiswick (1999), os imigrantes tendem a ser positivamente selecionados possuindo melhores características não observáveis, sendo descritos como em média mais capazes, motivados, ambiciosos, empreendedores, mais aptos do que os não migrantes. Por isso, estes ganhariam maiores salários do que os não migrantes, sobretudo, devido às diferenças desses atributos não observados.

Pesquisas acerca das mulheres migrantes no mercado de trabalho têm sido realizadas para diversos países. 0 primeiro estudo que avaliou a situação da mulher migrante foi elaborado por Long (1980) para os Estados Unidos. Os resultados mostraram que os salários das mulheres imigrantes eram cerca de $13 \%$ superiores aos das mulheres nativas, condicionados às suas características. Porém essa vantagem diminui com o tempo de permanência no país.

Posteriormente, o estudo de Boyd (1984) investigou pela primeira vez a dupla desvantagem das mulheres imigrantes na força de trabalho do Canadá, em 1973. Observou-se que as mulheres imigrantes tinham um status ocupacional inferior, em média, ao dos homens e nativos.

No que concerne aos salários, dois estudos canadenses estimaram o efeito negativo duplo sobre os salários das mulheres imigrantes. Beach e Worswick (1993) descobriram que algumas mulheres imigrantes, principalmente com maior nível de educação, sofriam dupla desvantagem salarial. Shamsuddin (1998) reportou que esse efeito negativo sobre a renda das mulheres era muito grande, porém, a discriminação de gênero era mais acentuada que aquela por local de nascimento.

Para a Dinamarca, Husted et al. (2000) avaliaram se existe um duplo efeito negativo sobre os ganhos das mulheres imigrantes decorrente da questão gênero e do fato de serem estrangeiras. Os autores verificaram que todas as mulheres são afetadas por 
uma discriminação substancial de gênero nos salários, mas apenas aquelas oriundas do Paquistão experimentam um duplo efeito negativo.

Hayfron (2002) investigou a possibilidade de uma desvantagem para as mulheres imigrantes no mercado de trabalho norueguês. A partir do tradicional método de Oaxaca-Blinder, o autor mostrou que existe um efeito negativo duplo sobre os salários das mulheres migrantes em razão de gênero e etnia.

Para a Espanha, Nicodemo e Ramos (2012) analisaram a diferença salarial entre as mulheres imigrantes e as nativas. Levando em conta a necessidade de controlar o suporte comum, foi utilizado o procedimento de Ñopo (2008). Os resultados sugeriram que, em média, as mulheres imigrantes ganham menos do que as nativas no mercado de trabalho espanhol. A principal conclusão deste estudo foi que parte dessa diferença salarial está relacionada com a diferença de suportes comuns, isto é, mulheres imigrantes têm características diferentes das nativas, o que as torna menos atraentes ao mercado de trabalho.

$\mathrm{Na}$ literatura nacional, podem ser citadas algumas pesquisas, apesar de não terem como foco principal a migração feminina: Batista e Cacciamali (2009), Assis e Alves (2014) e Rodrigues et al. (2015), que avaliam a diferença salarial por sexo segundo condição de migração interna. ${ }^{4}$

Batista e Cacciamali (2009), utilizando os dados da PNAD de 2005, aplicaram o índice de dissimilaridade de Duncan \& Duncan e a decomposição de Oaxaca para os salários de homens e mulheres migrantes e não migrantes. Os autores constataram que na região Sudeste, além da discrepância salarial por sexo, também existe uma segregação entre migrantes e não migrantes, tanto no mercado de trabalho feminino como no masculino. No restante do Brasil, a maior diferença de salários por sexo ocorre entre a população migrante.

Assis e Alves (2014) procuraram verificar se existe diferença salarial entre sexo e condição de migração, utilizando os dados da PNAD de 2009 e a mesma metodologia empregada por Batista e Cacciamali (2009). Os resultados mostraram que os homens são mais valorados pelo mercado em relação às mulheres, tanto no grupo de não migrantes como no de migrantes. 0 estudo também encontrou indícios de que grande parte das diferenças salariais entre homens e mulheres e entre migrantes deve-se à existência de discriminação no mercado de trabalho.

Vale destacar que Batista e Cacciamali (2009) e Assis e Alves (2014) fazem a análise da decomposição de Oaxaca para os diferenciais salariais segundo condição de migração e gênero para a região Sudeste e, posteriormente, para o Brasil sem o Sudeste, diferentemente desse estudo que analisa todas as regiões brasileiras.

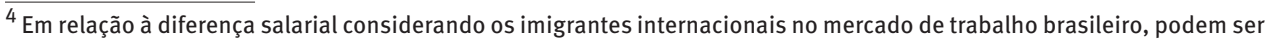
citados os estudos de Vilela (2011) e Noronha, Vilela e Campos (2019). 0 primeiro mostra que os imigrantes internacionais possuem vantagem salarial ou estão em condições iguais às dos nativos brasileiros. Já o segundo analisa especificamente bolivianos e nordestinos no mercado de trabalho paulista, indicando que os bolivianos possuem condição salarial mais vantajosa do que os nordestinos. Isso ocorre porque estes últimos são menos valorizados em termos dos seus atributos individuais.
} 
Por fim, Rodrigues et al. (2015) fizeram a mesma análise que os autores supracitados apenas para o estado da Bahia, a partir dos dados da PNAD de 2013. Os resultados revelaram que os trabalhadores migrantes no estado apresentavam salários superiores, tanto para os homens como para as mulheres, em comparação com os não migrantes. Os homens são mais valorizados no mercado de trabalho independentemente da sua condição de migração, sendo que a maior diferença salarial por sexo ocorre na população migrante.

Diante do exposto, este estudo avança em relação à literatura nacional por aplicar um método ainda não utilizado para a análise de diferencias de rendimentos segundo condição de migração (não migrante, migrante de retorno e migrante não natural), analisando para as regiões brasileiras, além de focar na migração das mulheres.

\section{Metodologia}

\section{Dados e tratamento}

Para realização do presente trabalho, as variáveis relacionadas às características pessoais, familiares, de mercado de trabalho e de residência são oriundas dos dados da Pesquisa Nacional por Amostra de Domicílios (PNAD) 2005 e 2015, realizada pelo IBGE.

A utilização da PNAD de periodicidade anual deve-se ao fato de a PNAD Contínua não abranger os aspectos demográficos relacionados à migração, até a realização do presente estudo. Além disso, a PNAD 2015 é a última pesquisa anual que inclui as questões migratórias. Para comparação dos salários das mulheres entre dois anos distintos, utilizou-se também a PNAD 2005.

Empregou-se o quesito "última etapa” para identificação dos migrantes, que correspondem às pessoas que trocaram de estado pelo menos uma vez nos últimos dez anos. Para tanto, foi verificado se o indivíduo morou em outra unidade da federação, tempo de residência na UF e lugar (UF) de residência anterior. Segundo Campos (2011), uma limitação dessa informação é não identificar o indivíduo que realizou uma outra etapa migratória, já que se investiga apenas a última etapa.

As classificações de migrantes foram definidas da seguinte maneira: não migrantes - indivíduos que nunca moraram fora da sua UF de nascimento; migrantes não naturais indivíduos oriundos de outros estados; e migrantes de retorno - indivíduos que tiveram alguma experiência de moradia fora do seu estado de nascimento, mas, no momento da pesquisa, encontravam-se residindo na UF de nascimento.

Foram realizados alguns filtros: selecionados os indivíduos com idade entre 15 e 65 anos de idade; ${ }^{5}$ excluídos os estrangeiros e brasileiros que declararam terem morado em outros países; e excluídos os indivíduos com renda nula e não declarada. 0 salário por

\footnotetext{
${ }^{5}$ Considerando a População em Idade Ativa (PIA) e pressupondo que a partir dos 65 anos de idade os indivíduos já estariam aposentados.
} 
hora foi deflacionado pelo Índice de Preço ao Consumidor Amplo (IPCA), ${ }^{6}$ tendo como base 2005, para fins de comparação entre os anos.

As variáveis utilizadas nesse estudo estão descritas no Anexo. Foram criados seis conjuntos de variáveis para a estimação da decomposição de Ñopo (2008), apresentados no Quadro 1.

QUADRO 1

Conjunto de variáveis consideradas na decomposição de Ñopo (2008)

\begin{tabular}{|ll|}
\hline Especificações & \multicolumn{1}{c|}{ Variáveis } \\
\hline Especificação 1 & Branco e dummies de idade \\
\hline Especificação 2 & Branco, dummies de idade e dummies de educação \\
\hline Especificação 3 & Branco, dummies de idade, dummies de educação, casal e filho5 (1) \\
\hline Especificação 4 & Branco, dummies de idade, dummies de educação, casal, filho5 e dummies de ocupação \\
\hline Especificação 5 & $\begin{array}{l}\text { Branco, dummies de idade, dummies de educação, casal, filho5, dummies de ocupação, } \\
\text { urbana, região metropolitana e dummies das regiões brasileiras (2) }\end{array}$ \\
\hline Especificação 6 & $\begin{array}{l}\text { Branco, dummies de idade, dummies de educação, casal, filho5, dummies de ocupação, } \\
\text { urbana, região metropolitana e dummies de tempo de residência (3) }\end{array}$ \\
\hline
\end{tabular}

Fonte: Elaboração dos autores.

(1) Variável inserida apenas na decomposição da diferença salarial entre mulheres migrantes e não migrantes, pois esta variável foi criada a partir das características de fecundidade.

(2) As dummies de regiões foram inseridas na especificação 5 apenas na análise referente aos Gráficos 3, 4, 5 e 6.

(3) A variável tempo de residência foi incorporada apenas nas decomposições para os migrantes: homem migrante de retorno versus mulher migrante de retorno; e homem migrante não natural versus mulher migrante não natural.

\section{Decomposição de Ñopo (2008)}

Este estudo segue o procedimento não paramétrico proposto por Ñopo (2008) que utiliza técnicas de pareamento, constituindo uma alternativa à decomposição de Oaxaca-Blinder (1973). Este método decompõe em quatro termos o diferencial total, destacando as diferenças nos suportes das distribuições.

Ñopo (2008) sugere que a decomposição de Oaxaca-Blinder superestimaria o componente do diferencial atribuído às diferenças não observáveis, uma vez que poderia haver combinações de características individuais que existem num grupo, mas inexistem em outro. Por exemplo, pode ser que haja combinações de características observáveis para as quais é possível encontrar mulheres, mas não homens. Da mesma maneira, o suporte da distribuição das características do grupo de migrantes pode ser diferente daquele referente aos não migrantes.

Esta metodologia não tem a necessidade de qualquer estimativa das equações de rendimentos. 0 diferencial é calculado a partir do valor esperado dos ganhos condicionados às características observáveis e da função de distribuição acumulada das características observáveis.

\footnotetext{
$\overline{6}$ Índice calculado pelo IBGE e obtido a partir do Ipeadata. Disponível em: http://www.ipeadata.gov.br.
} 
Para decompor a diferença salarial entre mulheres migrantes e nativas ${ }^{7}$ (análise de discriminação devido ao status de migrante), têm-se dois grupos distintos de mulheres: as nativas $(\mathrm{N})$ e as migrantes $(\mathrm{M})$. Considere $\mathrm{Y}$ uma variável aleatória dos rendimentos individuais e $X$ um vetor de características. Sejam $F^{N}\left(\right.$.) e $F^{M}($.) as funções de distribuição acumulada condicional, para as mulheres nativas e migrantes, respectivamente, $d F^{N}$ (.) e $d F^{M}$ (.) as respectivas medidas de probabilidades.

Inicialmente, como mostrado nas equações (1) e (2), calcula-se o valor esperado dos rendimentos, condicionado às características dos dois grupos:

$$
\begin{aligned}
& E[Y \mid N]=\int_{S^{N}} g^{N}(x) d F^{N}(x) \\
& E[Y \mid M]=\int_{S^{M}} g^{M}(x) d F^{M}(x)
\end{aligned}
$$

Onde: $S^{N}$ e $S^{M}$ representam o suporte de distribuição de características para as nativas e as migrantes, respectivamente. Dessa forma, o diferencial entre os salários é definido por:

$\Delta=E[Y \mid N]-E[Y \mid M]$

$\Delta=\int_{S^{N}} g^{N}(x) d F^{N}(x)-\int_{S^{M}} g^{M}(x) d F^{M}(x)$

A equação (4) é composta de quatro componentes, pois cada integral é decomposta em dois termos, dentro e fora do suporte comum.

$\Delta=\Delta_{N}+\Delta_{M}+\Delta_{X}+\Delta_{0}$

Onde:

$\Delta_{N}$ é a parte da diferença salarial que pode ser explicada pelas diferenças entre dois grupos de mulheres nativas: um que possui características que podem ser pareadas com as características das mulheres migrantes; e outro que não pode. Esse componente seria zero se todas as mulheres nativas fossem pareadas com as mulheres migrantes, ou seja, se nativas e migrantes fossem grupos bem parecidos com relação às suas características; $\Delta_{M}$ é a parte da diferença salarial que pode ser explicada pelas diferenças entre dois grupos de mulheres migrantes: um que possui características que podem ser pareadas com as características das mulheres nativas; e outro que não pode. $\Delta_{N}$ e $\Delta_{M}$ são componentes do hiato salarial que existem porque os conjuntos de características observáveis das mulheres nativas e migrantes não se sobrepõem completamente;

$\Delta_{X}$ é a parte da diferença salarial que pode ser explicada por diferenças na distribuição das características individuais das mulheres nativas e migrantes ao longo de suporte comum. Possui interpretação equivalente ao termo $\underbrace{\left(\bar{X}_{N}-\bar{X}_{M}\right) \hat{\beta}_{M}}$ da decomposição de Oaxaca-Blinder; $\underbrace{\left(X_{N}\right.}_{\text {efeito dotação }}$

$\Delta_{o}$ é equivalente à parte não explicada da decomposição de Oaxaca-Blinder $\underbrace{\bar{X}_{N}\left(\hat{\beta}_{N}-\hat{\beta}_{M}\right)}_{N}$. efeito discriminação

\footnotetext{
70 termo "nativas" refere-se às mulheres não migrantes. Foi inserido esse termo na metodologia seguindo Nicodemo e Ramos (2011).
} 
Esta diferença é atribuída às características não observáveis e/ou à discriminação entre as mulheres migrantes e as nativas. Esse componente corresponde à situação em que as mulheres migrantes e nativas possuem a mesma distribuição das características observáveis, porém, a disparidade salarial ainda permanece.

O algoritmo de pareamento sugerido por Ñopo (2008) é apresentado nas seguintes etapas:

1. uma mulher migrante é selecionada da amostra, sem reposição;

2. selecionam-se todas as mulheres nativas com características observáveis semelhantes às da mulher migrante previamente selecionada na etapa $1 ;$

3. constrói-se um “indivíduo sintético”, cujas características sejam iguais à média de todas aquelas selecionadas na etapa 2, e pareia-se este indivíduo sintético à mulher migrante da etapa 1 ;

4. a mulher migrante selecionada na etapa 1 e o indivíduo sintético são inseridos na nova amostra de indivíduos pareados;

5. repetem-se as etapas de 1 a 4 para cada mulher migrante.

No final de todo o procedimento a nova amostra conterá quatro tipos de indivíduos: mulheres migrantes pareadas; mulheres migrantes não pareadas; mulheres não migrantes (nativas) pareadas; e mulheres não migrantes (nativas) não pareadas.

Todo o processo descrito anteriormente será realizado para decompor a diferença salarial entre homens migrantes (M) e mulheres migrantes (F): $\Delta=E[Y \mid M]-E[Y \mid F]$ com o propósito de verificar se existe discriminação de gênero entre os migrantes interestaduais.

Para observar se há um efeito negativo duplo sobre os salários das mulheres migrantes, primeiro verificou-se a questão de gênero comparando os seguintes grupos: homem migrante de retorno vis-à-vis mulher migrante de retorno; e homem migrante não natural vis-à-vis mulher migrante não natural. 0 segundo efeito sobre os salários dessas mulheres refere-se ao status de migrante e, para isso, analisaram-se as seguintes categorias: mulher não migrante vis-à-vis mulher migrante de retorno; e mulher não migrante vis-à-vis mulher migrante não natural.

Para a realização desta técnica não é recomendável o uso de variáveis contínuas. Por isso, as variáveis contínuas utilizadas devem ser transformadas em variáveis categóricas ou, quando possível, em binárias.

\section{Resultados empíricos}

\section{Análise descritiva}

A Tabela 1 mostra as estatísticas descritivas para homens e mulheres segundo condição de migração (não migrantes, migrantes de retorno e migrantes não naturais) em 2005 e 2015. Referente à raça, em 2005, observou-se que a maioria das mulheres era branca; já 
o contrário se percebe em 2015. Os migrantes são mais velhos dos que os não migrantes, sendo que a maior proporção de migrantes tanto homens como mulheres estava na faixa etária entre 35 e 44 anos. Já os não migrantes encontravam-se, em sua maioria, no grupo de 25 a 34 anos.

Em 2005, no que concerne à educação, a maior proporção de mulheres tinha entre 11 e 14 anos de estudo, sendo que a exceção correspondia às migrantes não naturais, que na sua maioria tinham entre 5 e 10 anos de estudo. Os homens também estavam nesse grupo de anos de educação, sejam eles migrantes ou não. Já em 2015, tanto homens como mulheres tinham, em sua maioria, de 11 a 14 anos de estudo. Destaca-se a maior proporção de mulheres com 15 ou mais anos de estudo em comparação com os homens, nos dois anos analisados, indicando que as mulheres possuíam maior nível educacional.

Em relação à condição de migração, constatou-se que os migrantes de retorno, em ambos os anos, possuíam maior proporção de indivíduos com mais de 15 anos de estudo. Esse maior nível educacional dos migrantes de retorno pode relacionar-se com o investimento em capital humano. Segundo Borjas e Bratsberg (1996), a remigração ocorre se o prêmio no local de origem tiver se elevado depois da aquisição do capital humano ou novas habilidades. E por mais que esse retorno seja motivado por algum erro de previsão ou desemprego, esses migrantes obtêm um retorno econômico positivo no local de origem, ou seja, possuem um rendimento médio maior do que os não migrantes (RAMALHO; QUEIROZ, 2011).

Os indivíduos em sua maioria possuíam cônjuge, enfatizando que os migrantes não naturais tinham um percentual maior do que os demais. Com relação à variável filho5, que se refere à fecundidade das mulheres, observou-se que, em 2005, 17\% das mulheres não migrantes e aproximadamente $16 \%$ das migrantes tinham filhos menores de 5 anos de idade. Em 2015, além de esse percentual ser menor do que em 2005, ressalta-se que as mulheres não naturais ainda tinham entre todas a menor proporção (12,52\%), contra cerca de $14,6 \%$ para as não migrantes e de retorno.

No mercado de trabalho, em ambos os anos, a grande maioria das mulheres estava ocupada nos serviços e os homens eram trabalhadores da produção de bens e serviços e de reparação e manutenção. Em 2005, vale destacar ainda as seguintes ocupações para as mulheres: $15,13 \%$ das não migrantes eram trabalhadoras de serviços administrativos; $12,56 \%$ das retornadas eram profissionais das ciências e das artes; e 12,61\% das migrantes não naturais eram vendedoras e prestadoras de serviço do comércio.

Em 2005, a agricultura aparecia como o segundo maior setor ocupado pelos homens, sendo $19 \%$ para os não migrantes e migrantes de retorno e $14,26 \%$ para os não naturais. 0 mesmo se verificou em 2015, com exceção para os migrantes não naturais, que se incluíam mais como trabalhadores nos serviços do que na agricultura. 
TABELA 1

Estatística descritiva, por sexo e condição de migração, segundo variáveis selecionadas Brasil - 2005-2015

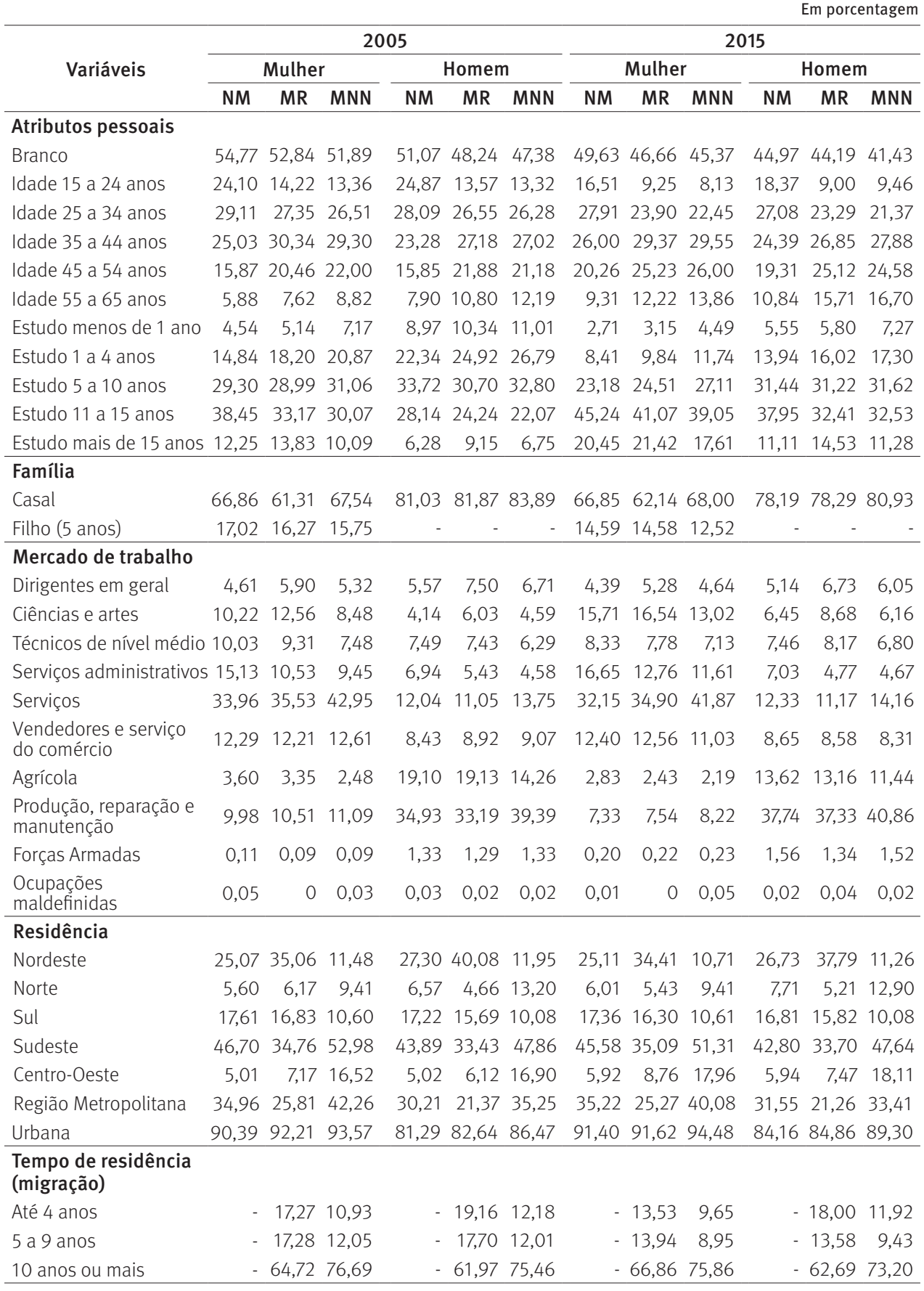

Fonte: IBGE. Pesquisa Nacional por Amostra de Domicílios (PNAD) 2005 e 2015. Elaboração dos autores. Nota: Resultados expandidos para a população.

$N M=$ não migrante; $M R=$ migrante de retorno; $M N N=$ migrante não natural. 
Em relação à residência, como mostra uma ampla literatura sobre migração de retorno, a maioria dos retornados se encontrava na região Nordeste, ${ }^{8}$ em 2005 , o mesmo ocorrendo em 2015, com uma pequena queda dessa proporção. Já os não migrantes e migrantes não naturais viviam em maior proporção no Sudeste, devido à grande densidade populacional da região. Entre os grupos analisados, os que menos residiam em região metropolitana eram os migrantes de retorno. Já os migrantes não naturais eram os que mais moravam em zona urbana.

No que concerne ao tempo de residência dos migrantes, a maior proporção vivia há mais de dez anos na unidade de federação, ou seja, são migrantes com mais tempo de residência no estado.

O Gráfico 1 mostra a densidade kernel do salário/hora dos migrantes de retorno e não naturais, segundo sexo, em 2005 e 2015. Identificou-se, para aqueles com menor nível de renda, que, em ambos os anos, os homens migrantes não naturais auferiam salários superiores aos das mulheres migrantes não naturais, porém com uma diferença maior em 2005.

Com relação aos migrantes de retorno, novamente os homens estavam em melhor situação do que as mulheres, tanto em 2005 quanto em 2015. Cabe ressaltar que os migrantes de retorno eram os que recebiam menores salários em comparação com os migrantes não naturais. Além disso, identificou-se uma desvantagem salarial para as mulheres migrantes, tanto para aquelas com maiores como menores níveis de rendimentos.

\section{GRÁFICO 1}

Densidade do salário/hora dos migrantes, segundo sexo

Brasil - 2005-2015

2005

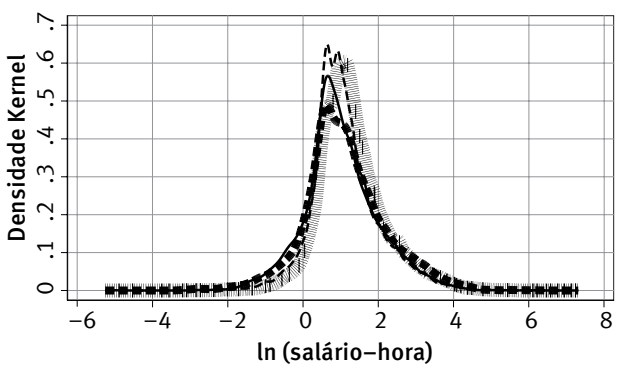

2015

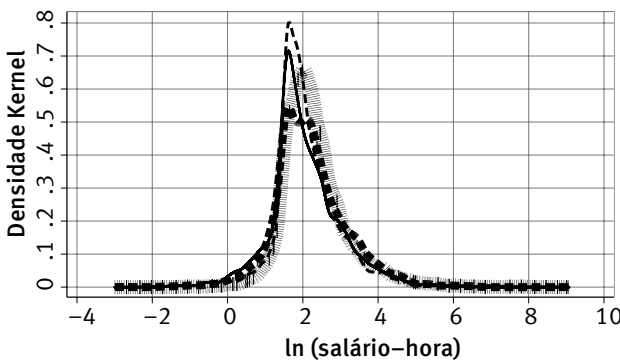

Mulheres retornadas

-1. Homens retornados --n. Mulheres migrantes não naturais

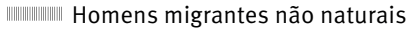

Fonte: IBGE. Pesquisa Nacional por Amostra de Domicílios (PNAD) 2005 e 2015. Elaboração dos autores.

Já no Gráfico 2 tem-se a comparação da densidade do salário/hora para as mulheres, segundo condição de migração, em 2005 e 2015. Para aquelas com menores níveis de rendimento, observou-se o mesmo comportamento em ambos os anos: as migrantes não

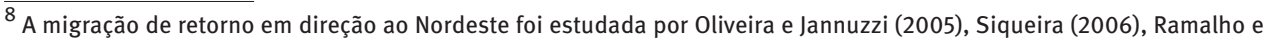
Neto (2009), Ojima e Nascimento (2015) e Aguiar e França (2017).
} 
naturais encontravam-se em situação melhor no que concerne aos seus salários, seguidas pelas não migrantes e por fim as retornadas. Para as mulheres com nível salarial alto, os salários para os grupos analisados não diferiam.

GRÁFICO 2

Densidade do salário/hora das mulheres, segundo condição de migração Brasil - 2005-2015

2005

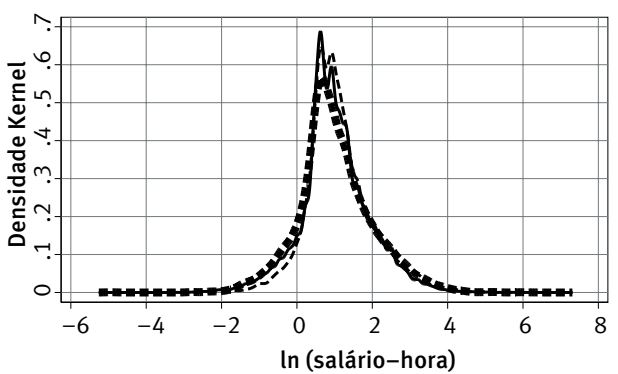

2015

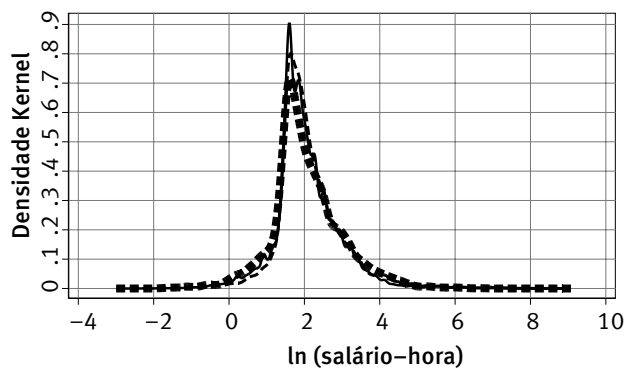

\footnotetext{
- Mulheres não migrantes

--- Mulheres migrantes não naturais

-... Mulheres retornadas
}

Fonte: IBGE. Pesquisa Nacional por Amostra de Domicílios (PNAD) 2005 e 2015. Elaboração dos autores.

\section{Decomposição das diferenças salariais}

Os Gráficos 3 e 4 mostram os resultados da decomposição de Ñopo (2008), segundo sexo, para os migrantes de retorno e não naturais, em 2005 e 2015, estimados para cada conjunto de variáveis (contidos no Quadro 1).

Vale salientar que quanto maior o número de variáveis utilizadas menor é a probabilidade de encontrar correspondência no pareamento (ATAL; ÑOPO; WINDER, 2010). Assim como exposto por Nicodemo e Ramos (2011), esse problema é acentuado quando se inserem as características do trabalho. Como as mulheres tendem a se inserir em ocupações diferentes das dos homens, bem como as ocupações dos migrantes podem ser divergentes daquelas dos nativos (devido à escolaridade, cultura, etc.), a decomposição de Oaxaca-Blinder não reconhece essas diferenças nos suportes.

A parte do diferencial salarial comum no suporte $(\Delta \mathrm{X})$ foi negativo em todas as seis especificações (Gráficos 3 e 4). Isso mostra que as mulheres migrantes tinham características observáveis relativamente melhores do que os homens migrantes. Essa evidência se destaca quando se inserem as dummies de educação, ou seja, na segunda especificação, mostrando que as mulheres deveriam receber maiores retornos no mercado de trabalho por possuírem maior nível educacional. Este resultado está de acordo com a literatura sobre diferenciais salariais segundo gênero (LEME; WAJNMAN, 2000; GARCIA; ÑOPO; SALARDI, 2009; PASCHOALINO; PLASSA; SANTOS, 2017). 
Os gráficos mostram ainda que, após a inserção das variáveis de tempo de residência contidas na especificação 6 , o componente $\Delta M$ mostrou-se negativo, indicando que as mulheres podiam ter acesso a alguns segmentos que as remuneravam melhor nas regiões brasileiras com o passar dos anos no local de destino.

\section{GRÁFICO 3}

Diferença salarial entre homens e mulheres migrantes de retorno Brasil - 2005-2015

Homem migrante $\mathrm{x}$ mulher migrante
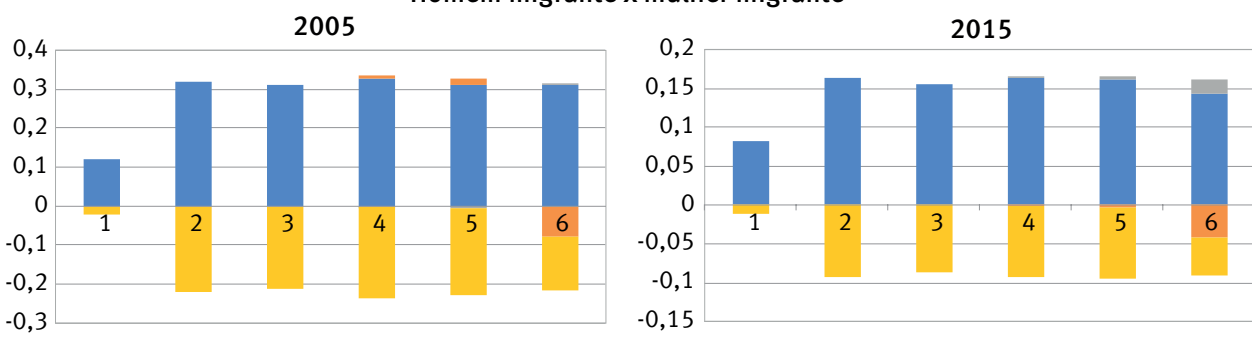

$\Delta 0 \quad \Delta \mathrm{M} \quad \Delta \mathrm{F} \quad \Delta \mathrm{X}$

Fonte: IBGE. Pesquisa Nacional por Amostra de Domicílios (PNAD) 2005 e 2015. Elaboração dos autores. Nota: Resultados expandidos para a população.

\section{GRÁFICO 4}

Diferença salarial entre homens e mulheres migrantes não naturais

Brasil - 2005-2015

2005

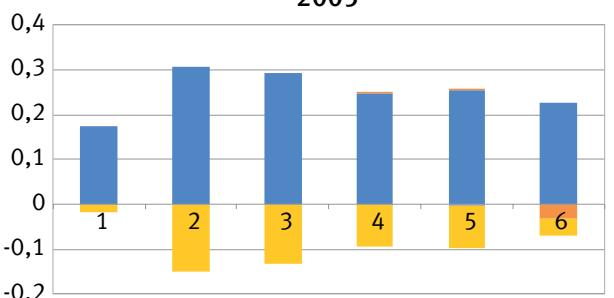

2015

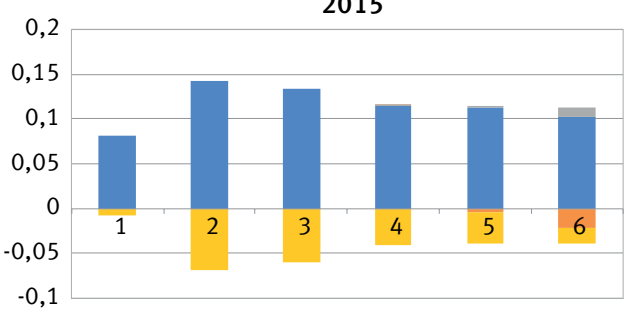

$-0,1$

$\Delta 0 \quad \Delta \mathrm{M} \quad \Delta \mathrm{F} \quad \Delta \mathrm{X}$

Fonte: IBGE. Pesquisa Nacional por Amostra de Domicílios (PNAD) 2005 e 2015. Elaboração dos autores. Nota: Resultados expandidos para a população.

Já nos Gráficos 5 e 6 têm-se os resultados da decomposição de Ñopo (2008) para as mulheres segundo condição de migração (migrantes de retorno e migrantes não naturais) em 2005 e 2015, estimados para cinco conjuntos de variáveis. ${ }^{9}$

A decomposição para as mulheres não migrantes em relação às migrantes de retorno (Gráfico 5) mostra que, dentro do suporte comum, a parte do diferencial referente às características observáveis $(\Delta \mathrm{X})$ é negativa em todas as especificações, em ambos os anos

\footnotetext{
${ }^{9}$ Como já mencionado na metodologia, para as mulheres não foram inseridas as dummies de residência (contidas na especificação 6), pois comparam-se as mulheres migrantes com as não migrantes. E no caso dessas últimas, elas nunca residiram fora da UF de nascimento.
} 
analisados. Este achado revela que as mulheres migrantes de retorno possuíam melhores características observáveis se comparadas com as não migrantes, principalmente quando se acrescentam as dummies de educação (especificação 2 ) e as variáveis de ocupação (especificação 4).

Isso demonstra que a diferença salarial em favor das mulheres migrantes de retorno pode ser explicada, em parte, pela maior acumulação de capital humano, como demonstrado também por Fridsén e Sjölander (2018), além da escolha ocupacional desse grupo. Como já demonstrado na estatística descritiva (Tabela 1), as mulheres migrantes de retorno eram as que possuíam maior nível de educação em comparação com as não migrantes e migrantes não naturais.

GRÁFICO 5

Diferença salarial entre as mulheres não migrantes e as migrantes de retorno

Brasil - 2005-2015

Mulher não migrante $\mathrm{x}$ mulher migrante de retorno

2005

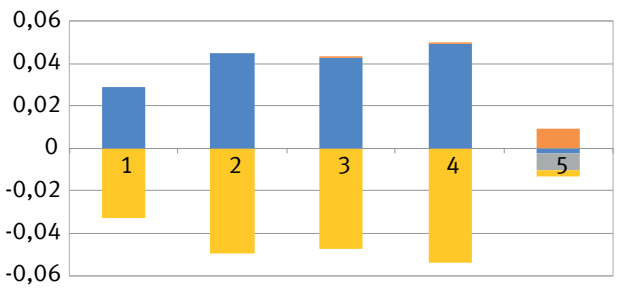

2015

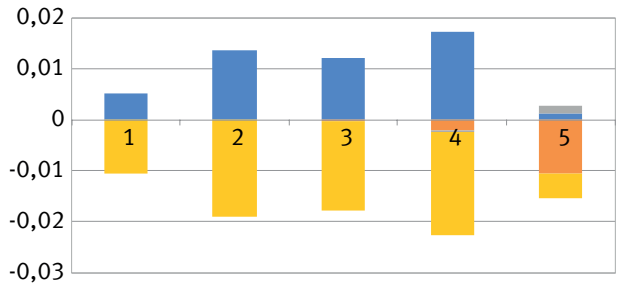

$-0,03$

Fonte: IBGE. Pesquisa Nacional por Amostra de Domicílios (PNAD) 2005 e 2015. Elaboração dos autores. Nota: Resultados expandidos para a população.

GRÁFICO 6

Diferença salarial entre as mulheres não migrantes e as migrantes não naturais Brasil - 2005-2015

Mulher não migrante $\mathrm{x}$ mulher migrante não natural
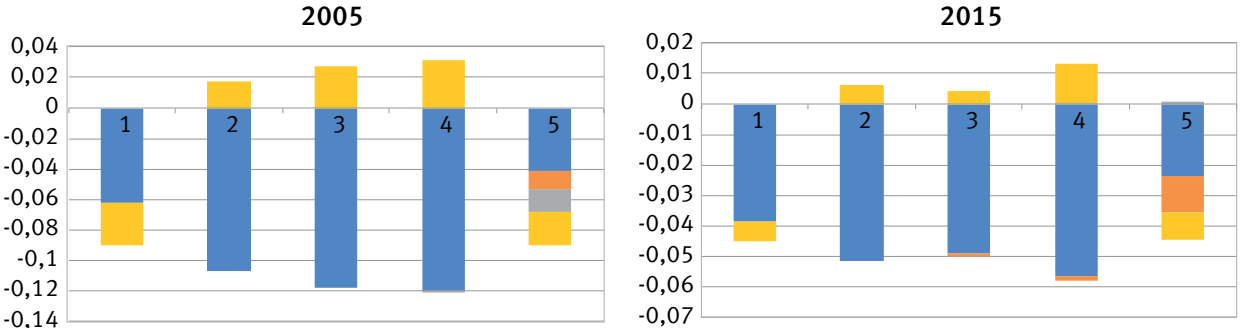

$\square 0 \square \Delta \mathrm{M} \quad \Delta \mathrm{F} \square \Delta \mathrm{X}$

Fonte: IBGE. Pesquisa Nacional por Amostra de Domicílios (PNAD) 2005 e 2015. Elaboração dos autores. Nota: Resultados expandidos para a população.

No Gráfico 6, relativo à decomposição de Ñopo (2008) para as mulheres não migrantes em comparação com as migrantes não naturais, verifica-se que o componente não 
explicativo $(\Delta 0)$ é negativo em ambos os anos, em todas as cinco especificações. Isso sugere que as mulheres migrantes não naturais possuíam melhores características não observáveis que as remuneravam melhor no mercado de trabalho do que as não migrantes. Este achado vai ao encontro do que sugerem Assis e Alves (2014), que, apesar de analisarem o Brasil sem a região Sudeste, encontraram um diferencial não explicado negativo, sendo responsável por $32,86 \%$ do diferencial total em favor das mulheres migrantes.

As Tabelas 2 e 3 mostram os resultados do pareamento de Ñopo (2008) para o conjunto completo das variáveis observáveis para as regiões brasileiras, em 2005 e 2015.

Verificou-se, por meio da especificação 6, na Tabela 2, que o diferencial total de rendimento para o homem migrante de retorno em relação à mulher de mesma condição foi positivo para todas as regiões, exceto para o Nordeste em 2005. Esse componente positivo para as regiões indica uma vantagem salarial para os homens frente às mulheres, mas esse diferencial total diminui ao longo dos anos. Cabe destacar o diferencial total negativo na região Nordeste em 2005, indicando que as mulheres migrantes de retorno eram mais bem remuneradas do que os homens nessa mesma condição, apesar de essa diferença ser de apenas $-0,0724$.

Já para os migrantes não naturais, os diferenciais salariais para todas as regiões mostraram-se positivos. Apenas para o Nordeste não se observou redução expressiva do diferencial total segundo sexo, ao longo dos anos (passando de 0,1078 para 0,1022 ).

Ressalta-se que, em 2005, o Nordeste apresentava a menor desigualdade salarial entre sexo no grupo de migrantes não naturais. Essa evidência também foi observada por Assis e Alves (2014). No entanto, em 2015, notou-se nessa região uma maior segregação salarial entre homens e mulheres migrantes não naturais. Para as demais regiões houve relevante redução do diferencial de rendimentos entre os sexos. Deve-se destacar o Sudeste, que passou de um diferencial de 0,1960, em 2005, para 0,0860, em 2015.

0 diferencial não explicado $(\Delta 0)$ age no sentido de aumentar o "gap" existente entre homens e mulheres tanto para os migrantes de retorno como para os não naturais, enquanto o diferencial devido às características observáveis $(\Delta \mathrm{X})$ reduzem esse diferencial.

Percebe-se que houve um diferencial salarial entre homens e mulheres nas regiões brasileiras, em favor dos homens, mas esse diferencial apresentou redução na comparação entre 2005 e 2015. Tal resultado está de acordo com o encontrado por Faustino, Araújo e Maia (2017), que também observaram uma queda da diferença salarial e da discriminação por gênero no Brasil, entre 2004 e 2014.

A Tabela 3 apresenta o resultado da decomposição para as mulheres segundo condição de migração (mulher não migrante $x$ mulher migrante de retorno; e mulher não migrante $x$ mulher migrante não natural) para a especificação 5. Dessa forma, o sinal negativo para o diferencial total indica que as mulheres migrantes de retorno possuíam uma vantagem salarial em relação às não migrantes em todas as regiões brasileiras. Esse diferencial é explicado, em maior parte, pelas características não observadas $(\Delta 0)$, com exceção da região Nordeste em 2015. Na análise para o Brasil, autores como Ramalho e Queiroz (2011), 
Ferreira (2012) e Alencar, Puchale e Porto Jr. (2020) também verificaram que os migrantes de retorno têm maiores salários do que os não migrantes devido aos atributos não observados.

TABELA 2

Decomposição de Ñopo (2008), por sexo e condição de migração

Brasil - 2005-2015

\begin{tabular}{|c|c|c|c|c|c|c|c|c|c|c|}
\hline \multicolumn{11}{|c|}{ Homem migrante de retorno $x$ mulher migrante de retorno } \\
\hline & \multicolumn{5}{|c|}{2005} & \multicolumn{5}{|c|}{2015} \\
\hline & NO & NE & SE & SU & $\mathrm{CO}$ & NO & NE & SE & SU & $\mathrm{CO}$ \\
\hline$\Delta$ & 0,1655 & $-0,0724$ & 0,2062 & 0,2050 & 0,1889 & 0,0578 & 0,0622 & 0,0877 & 0,1027 & 0,0860 \\
\hline$\Delta 0$ & 0,3143 & 0,3305 & 0,2856 & 0,2982 & 0,2815 & 0,1098 & 0,1456 & 0,1125 & 0,1565 & 0,1123 \\
\hline$\Delta \mathrm{M}$ & $-0,0488$ & $-0,1711$ & $-0,0441$ & $-0,0407$ & $-0,0154$ & $-0,0282$ & $-0,0662$ & $-0,0124$ & $-0,0355$ & $-0,0229$ \\
\hline$\Delta \mathrm{F}$ & $-0,0141$ & 0,0184 & 0,0029 & 0,0066 & $-0,0008$ & 0,0199 & 0,0270 & 0,0055 & 0,0148 & 0,0154 \\
\hline$\Delta X$ & $-0,0859$ & $-0,2502$ & $-0,0383$ & $-0,0591$ & $-0,0763$ & $-0,0437$ & $-0,0442$ & $-0,0178$ & $-0,0331$ & $-0,0189$ \\
\hline $\mathrm{DE}$ & $-0,1488$ & $-0,4029$ & $-0,0794$ & $-0,0932$ & $-0,0925$ & $-0,0520$ & $-0,0834$ & $-0,0247$ & $-0,0538$ & $-0,0263$ \\
\hline DNE & 0,3143 & 0,3305 & 0,2856 & 0,2982 & 0,2815 & 0,1098 & 0,1456 & 0,1125 & 0,1565 & 0,1123 \\
\hline \multicolumn{11}{|c|}{ Homem migrante não natural $x$ mulher migrante não natural } \\
\hline & \multicolumn{5}{|c|}{2005} & \multicolumn{5}{|c|}{2015} \\
\hline & NO & NE & SE & SU & $\mathrm{CO}$ & NO & NE & SE & SU & $\mathrm{CO}$ \\
\hline$\Delta$ & 0,1334 & 0,1078 & 0,1960 & 0,1710 & 0,1208 & 0,0223 & 0,1022 & 0,0860 & 0,0859 & 0,0731 \\
\hline$\Delta 0$ & 0,2413 & 0,3414 & 0,2012 & 0,2725 & 0,1914 & 0,0758 & 0,1917 & 0,0955 & 0,1126 & 0,1161 \\
\hline$\Delta M$ & $-0,0025$ & $-0,0194$ & $-0,0099$ & $-0,0131$ & 0,0012 & $-0,0052$ & $-0,0199$ & $-0,0063$ & $-0,0082$ & $-0,0053$ \\
\hline$\Delta F$ & $-0,0062$ & 0,0085 & $-0,0028$ & $-0,0009$ & $-0,0034$ & 0,0030 & 0,0077 & $-0,0016$ & 0,0065 & 0,0040 \\
\hline$\Delta X$ & $-0,0993$ & $-0,2227$ & 0,0074 & $-0,0876$ & $-0,0684$ & $-0,0512$ & $-0,0773$ & $-0,0016$ & $-0,0251$ & $-0,0416$ \\
\hline $\mathrm{DE}$ & $-0,1079$ & $-0,2336$ & $-0,0052$ & $-0,1016$ & $-0,0707$ & $-0,0535$ & $-0,0895$ & $-0,0095$ & $-0,0267$ & $-0,0430$ \\
\hline DNE & 0,2413 & 0,3414 & 0,2012 & 0,2725 & 0,1914 & 0,0758 & 0,1917 & 0,0955 & 0,1126 & 0,1161 \\
\hline
\end{tabular}

Fonte: IBGE. Pesquisa Nacional por Amostra de Domicílios (PNAD) 2005 e 2015. Elaboração dos autores. Nota: Resultados expandidos para a população.

$\Delta$ : diferencial total; $D E=\Delta M+\Delta F+\Delta X$ : diferencial explicado; DNE: diferencial não explicado.

Percebe -se, na comparação entre 2005 e 2015, que apenas para o Sudeste e Sul essa diferença salarial teve um pequeno aumento. Para as demais regiões, observou-se redução dessa diferença, com destaque para o Nordeste, que passou de um diferencial total de -0,1752, em 2005, para cerca de -0,0108, em 2015.

TABELA 3

Decomposição de Ñopo (2008) para as mulheres, por condição de migração Brasil - 2005-2015

\begin{tabular}{|c|c|c|c|c|c|c|c|c|c|c|}
\hline & \multicolumn{10}{|c|}{ Mulher não migrante $x$ mulher migrante de retorno } \\
\hline & \multicolumn{5}{|c|}{2005} & \multicolumn{5}{|c|}{2015} \\
\hline & NO & NE & SE & SU & $\mathrm{CO}$ & NO & $\mathrm{NE}$ & SE & SU & $\mathrm{CO}$ \\
\hline$\Delta$ & $-0,1411$ & $-0,1752$ & $-0,0157$ & $-0,0287$ & $-0,1185$ & $-0,0686$ & $-0,0108$ & $-0,0311$ & $-0,0317$ & $-0,0527$ \\
\hline$\Delta 0$ & $-0,1231$ & $-0,1149$ & $-0,0386$ & $-0,0401$ & $-0,1549$ & $-0,0667$ & $-0,0005$ & $-0,0384$ & $-0,0323$ & $-0,0606$ \\
\hline$\Delta \mathrm{N}$ & $-0,0021$ & $-0,0608$ & $-0,0067$ & $-0,0147$ & 0,0231 & $-0,0076$ & $-0,0285$ & $-0,0053$ & $-0,0106$ & 0,0011 \\
\hline$\Delta \mathrm{M}$ & $-0,0151$ & 0,0006 & 0,0037 & 0,0026 & $-0,0058$ & $-0,0015$ & 0,0073 & 0,0011 & 0,001 & $-0,0039$ \\
\hline$\Delta X$ & $-0,0008$ & $-0,0001$ & 0,0259 & 0,0235 & 0,0191 & 0,0072 & 0,0109 & 0,0115 & 0,0102 & 0,0107 \\
\hline DE & $-0,0180$ & $-0,0603$ & 0,0229 & 0,0114 & 0,0364 & $-0,0019$ & $-0,0103$ & 0,0073 & 0,0006 & 0,0079 \\
\hline DNE & $-0,1231$ & $-0,1149$ & $-0,0386$ & $-0,0401$ & $-0,1549$ & $-0,0667$ & $-0,0005$ & $-0,0384$ & $-0,0323$ & $-0,0606$ \\
\hline
\end{tabular}


(Continuação)

\begin{tabular}{|c|c|c|c|c|c|c|c|c|c|c|}
\hline & \multicolumn{10}{|c|}{ Mulher não migrante $\mathrm{x}$ mulher migrante não natural } \\
\hline & \multicolumn{5}{|c|}{2005} & \multicolumn{5}{|c|}{2015} \\
\hline & NO & NE & SE & SU & $\mathrm{CO}$ & NO & NE & SE & SU & $\mathrm{CO}$ \\
\hline$\Delta$ & $-0,1034$ & $-0,3332$ & 0,0757 & $-0,0792$ & $-0,1586$ & $-0,0765$ & $-0,0822$ & 0,0227 & $-0,0451$ & $-0,0475$ \\
\hline$\Delta 0$ & $-0,1001$ & $-0,3042$ & 0,0513 & $-0,0995$ & $-0,1769$ & $-0,0853$ & $-0,0791$ & 0,0116 & $-0,0518$ & $-0,0553$ \\
\hline$\Delta \mathrm{N}$ & $-0,0025$ & $-0,0386$ & $-0,0051$ & $-0,0074$ & 0,0082 & $-0,0029$ & $-0,0193$ & $-0,0041$ & $-0,0069$ & $-0,0005$ \\
\hline$\Delta \mathrm{M}$ & $-0,0064$ & 0,0033 & $-0,0029$ & $-0,0002$ & $-0,0033$ & 0,0029 & 0,0069 & 0,0005 & 0,0037 & 0,0012 \\
\hline$\Delta X$ & 0,0056 & 0,0063 & 0,0324 & 0,0279 & 0,0134 & 0,0088 & 0,0093 & 0,0147 & 0,0099 & 0,0071 \\
\hline $\mathrm{DE}$ & $-0,0033$ & $-0,029$ & 0,0244 & 0,0203 & 0,0183 & 0,0088 & $-0,0031$ & 0,0111 & 0,0067 & 0,0078 \\
\hline DNE & $-0,1001$ & $-0,3042$ & 0,0513 & $-0,0995$ & $-0,1769$ & $-0,0853$ & $-0,0791$ & 0,0116 & $-0,0518$ & $-0,0553$ \\
\hline
\end{tabular}

Fonte: IBGE. Pesquisa Nacional por Amostra de Domicílios (PNAD) 2005 e 2015. Elaboração dos autores. Nota: Resultados expandidos para a população.

$\Delta$ : diferencial total; $D E=\Delta N+\Delta M+\Delta X$ : diferencial explicado; DNE: diferencial não explicado.

Para a análise da diferença salarial das mulheres não migrantes versus mulheres migrantes não naturais, verificou-se que, tanto em 2005 como em 2015, apenas o Sudeste apresentou um diferencial total $(\Delta)$ positivo. Esse achado indica que as mulheres não migrantes auferiam maiores salários em comparação com as migrantes não naturais dos estados dessa região. Portanto, no Sudeste, as mulheres naturais dos seus estados eram mais bem remuneradas do que aquelas oriundas das outras regiões (migrantes não naturais). No entanto, essa diferença teve redução ao longo dos anos analisados, passando de cerca de 0,08 para 0,02 .

Vilela (2011), que analisou a imigração internacional no Brasil, sugere que a discriminação no mercado de trabalho contra os imigrantes é maior quando o país de origem possui uma situação econômica inferior ao país receptor. Já Schmidt Filho, Monte e Miceli (2009), seguindo a mesma lógica do estudo anterior, indicaram que houve diferença salarial entre o trabalhador nativo de uma região mais desenvolvida e o trabalhador migrante de uma região menos desenvolvida, com vantagem para o nativo. Vale mencionar que o estudo supracitado pesquisa a migração interna, em que o trabalhador nativo era o paulista e o migrante era o nordestino.

Segundo Loureiro (2018), as regiões Sudeste e Centro-Oeste eram as que mais penalizavam os trabalhadores nordestinos com menores salários. Com base na PNAD 2005, Batista e Cacciamali (2009) mostraram que 51,59\% dos migrantes que se encontravam no Sudeste tinham como origem o Nordeste. A partir dos dados da PNAD 2015, Lima e Teixeira (2020) observaram que a maioria dos migrantes na região Sudeste era oriunda do Nordeste, cerca de $74 \%$.

Visto que em ambos os anos, 2005 e 2015, o Sudeste teve mais migrantes provenientes do Nordeste, isso justificaria a desvantagem salarial para as mulheres migrantes não naturais do Sudeste. Este achado segue o mesmo raciocínio de Schmidt Filho, Monte e Miceli (2009) e Vilela (2011) sobre o fato de o desenvolvimento econômico da região de destino (Sudeste) ser maior do que da região de origem (Nordeste) acarreta a desvantagem das mulheres migrantes no mercado de trabalho na região receptora. 
Para o restante do país, observou-se o contrário: as mulheres migrantes não naturais dispunham de uma vantagem salarial em relação às não migrantes em ambos os anos. Porém, verificou-se que esse diferencial total em favor do grupo de mulheres não migrantes teve redução na comparação entre 2005 e 2015.

A região Nordeste se destaca, pois teve, em módulo, um maior diferencial total dos salários entre os grupos de mulheres analisados, favorecendo as migrantes. A exceção a este achado foi o ano de 2015 na comparação entre mulher não migrante versus mulher migrante de retorno, tendo a região Norte o maior diferencial total, em favor da mulher migrante de retorno. De um modo geral, a região Nordeste foi a que melhor remunerou as mulheres migrantes, sejam elas de retorno ou não naturais.

Conclui-se que apenas a mulher migrante não natural no Sudeste sofre de dupla desvantagem no mercado de trabalho. A primeira desigualdade salarial refere-se à questão de gênero e ocorre também nas demais regiões brasileiras. A segunda desvantagem salarial deve-se à condição de migrante (não natural do Sudeste), já que para as mulheres migrantes de retorno nessa região a situação foi diferente, ou seja, obtiveram uma vantagem salarial em comparação com as não migrantes. Este achado corrobora o que já haviam encontrado Batista e Cacciamali (2009), de que no Sudeste há uma discrepância salarial por sexo e entre migrantes e não migrantes, tanto no mercado de trabalho masculino como no feminino.

\section{Considerações finais}

0 presente estudo teve por objetivo verificar se existe um efeito negativo duplo sobre os salários das mulheres migrantes nas regiões brasileiras, bem como comparar o diferencial de salários segundo sexo e status de migração em 2005 e 2015. Para tanto, utilizou-se o método não paramétrico de Ñopo (2008) aplicado aos dados das PNADs de 2005 e 2015. Este método é uma alternativa à decomposição de Oaxaca-Blinder e decompõe em quatro termos o diferencial total.

Da análise descritiva para todas as condições de migração, destaca-se a maior proporção de mulheres com 15 anos ou mais de estudo em comparação com os homens, nos dois anos analisados. No mercado de trabalho, tanto em 2005 como em 2015, a grande maioria das mulheres estava ocupada nos serviços e os homens eram trabalhadores da produção de bens e serviços, e de reparação e manutenção.

No que concerne aos achados das decomposições, verifica-se que o diferencial de rendimento segundo sexo para os migrantes de retorno e não naturais foi positivo. Esse componente positivo indica que, para todas as regiões, existe uma vantagem salarial para os homens em relação às mulheres, porém esse hiato apresentou redução entre 2005 e 2015.

0 resultado negativo para o diferencial total de rendimento segundo condição de migração indica que as mulheres migrantes de retorno possuem uma vantagem salarial na comparação com as não migrantes em todas as regiões brasileiras. 
Já na análise da diferença salarial das mulheres não migrantes versus mulheres migrantes não naturais, verificou-se que apenas a região Sudeste apresentou resultado positivo, tanto em 2005 como em 2015, indicando que as mulheres não migrantes auferiam maiores salários do que as migrantes não naturais dos estados desta região. Portanto, no Sudeste, as mulheres naturais dos seus estados eram mais bem remuneradas do que aquelas que vêm das outras regiões.

Conclui-se, portanto, que apenas a mulher migrante não natural no Sudeste sofre dupla desvantagem no mercado de trabalho brasileiro. A primeira desigualdade salarial refere-se à questão de gênero e ocorre também nas demais regiões brasileiras. A segunda desvantagem salarial deve-se à condição de migrante (não natural do Sudeste), já que para as mulheres migrantes de retorno nessa região a situação foi diferente.

Cabe ressaltar a importância das políticas públicas voltadas para o mercado de trabalho brasileiro que trate dos desafios enfrentados pelas mulheres migrantes, seja relacionado ao hiato salarial entre gênero que ocorre em todas as regiões, seja devido à discrepância salarial em função da condição de migrante não natural na região Sudeste.

Tendo em vista que a literatura internacional sugere que as mulheres migrantes tendem a se inserir em empregos menos valorizados do que os dos homens migrantes, deixa-se como sugestão a análise das ocupações das mulheres migrantes no Brasil.

\section{Referências}

AGUIAR, M. A. S.; FRANÇA, J. M. S. Impacto da migração de retorno sobre a distribuição salarial: análise para os migrantes da região nordeste. In: ENCONTRO NACIONAL SOBRE MIGRAÇÃO, 10. Anais [...]. Natal: Blucher, 2017. P. 139-156. Disponivel em: http://www.proceedings.blucher. com.br/article-details/impacto-da-migrao-de-retorno-sobre-a-distribuio-salarial-anlise-paraos-migrantes-da-regio-nordeste-27584.

AGUIAR, M. A. S.; DE SOUSA, D. T.; RODRIGUES, P. S. Diferenciais de salários na região Nordeste: uma análise segundo condição de migração e nível educacional. Revista Brasileira de Estudos Regionais e Urbanos, v. 12, n. 4, p. 436-452, 2018.

AIGNER, D. J.; CAIN, G. G. Statistical theories of discrimination in labor markets. Industrial and Labor Relations Review, v. 30, n. 2, p. 175-187, 1977.

ALENCAR, M. O.; PUCHALE, C. L.; PORTO JR., S. S. Diferencial de rendimentos e migração de retorno nas macrorregiões brasileiras: uma análise a partir de diferentes aspectos individuais e socioeconômicos. In: ENCONTRO NACIONAL DE ECONOMIA, 48 [on-line]. Anais [...]. Anpec: 2020.

ASSIS, G. de O. Mulheres migrantes no passado e no presente: gênero, redes sociais e migração internacional. Revista Estudos Feministas, v. 15, n. 3, p. 745-772, 2007. Disponível em: https:// doi.org/10.1590/S0104-026X2007000300015.

ASSIS, R. S.; ALVES, J. S. Hiato salarial entre homens e mulheres no Brasil segundo condição migratória: o mercado de trabalho é segregado ou discrimina? Revista Econômica do Nordeste, v. 45, n. 1, p. 120-135, 2014.

ATAL, J. P.; ÑOPO, H.; WINDER, N. Gender and ethnic wage gaps in Latin America at the turn of the century. Inter-American Development Bank, 2010. 
BATISTA, N. N. F.; CACCIAMALI, M. C. Diferencial de salários entre homens e mulheres segundo a condição de migração. Revista Brasileira de Estudos de População, v. 26, n. 1, p. 97-115, 2009.

BEACH, C. M.; WORSWICK, C. Is there a double-negative effect on the earnings of immigrant women? Canadian Public Policy, v. 19, n. 1, p. 36-53, 1993.

BECKER, G. S. The economics of discrimination. Chicago: University of Chicago Press, 1957.

BOYD, M. At a disadvantage: the occupational attainments of foreign born women in Canada. International Migration Review, v. 18, n. 4, p. 1091-1119, 1984.

BORJAS, G. J.; BRATSBERG, B. Who leaves? The outmigration of the foreign-born. The Review of Economics and Statistics, v. 87, n. 1, p. 165-176, 1996.

BORJAS, G. J. Labor economics. 3th. ed. McGraw-Hill/Irwin, 2004.

CAMPOS, M. B. de. Estimativas de migração internacional no Brasil: os velhos e os novos desafios. In: OLIVEIRA, L. A. P. de; OLIVEIRA, A. T. R. de (org.). Reflexões sobre os deslocamentos populacionais no Brasil. Rio de Janeiro: IBGE, 2011.

CHISWICK, B. Are immigrants favorably self-selected? American Economic Review, v. 89, n. 2, p. 181-185, 1999.

FAUSTINO, I.; ARAÚJO, E.; MAIA, K. Mercado de trabalho e discriminação: uma análise das diferenças salariais e discriminação por gênero no Brasil e macrorregiões (2004-2014). In: ENCONTRO NACIONAL DE ECONOMIA, 45. Anais [...]. Natal: Anpec, 2017.

FERREIRA, A. de A. et al. Ensaios sobre a migração de retorno interestadual no Brasil. Dissertação (Mestrado em Economia) - Universidade Federal da Paraíba, João Pessoa, PB, 2012.

FRIDSÉN, E.; SJÖLANDER, V. The double disadvantage effect for immigrant women: is there an earnings differential between native women and immigrant women with similar education and human capital in the Swedish labour market? Bachelor Thesis. Linnaeus University, Sweden, 2018.

GAMA, L. C. D.; HERMETO, A. M. Diferencial de ganhos entre migrantes e não migrantes em Minas Gerais. Revista Brasileira de Estudos de População, v. 34, n. 2, p. 341-366, 2017.

GARCIA, L. M.; ÑOPO, H.; SALARDI, P. Gender and racial wage gaps in Brazil 1996-2006: evidence using a matching comparisons approach. Washington, DC: Inter-American Development Bank, 2009. (Working Paper, n. 681).

GIUBERTI, A. C.; MENEZES-FILHO, N. Discriminação de rendimentos por gênero: uma comparação entre o Brasil e os Estados Unidos. Economia Aplicada, v. 9, n. 3, p. 369-384, 2005.

HAYFRON, J. E. Panel estimates of the earnings gap in Norway: do female immigrants experience a double earnings penalty? Applied Economics, v. 34, n. 11, p. 1441-1452, 2002.

HUSTED, L. et al. Hit twice? Danish evidence on the double-negative effect on the wages of immigrant women. Centre for Labour Market and Social Research, 2000.

LE, A. T.; MILLER, P. W. Glass ceiling and double disadvantage effects: women in the US labour market. Applied Economics, v. 42, n. 5, p. 603-613, 2010.

LEME, M. C. da S.; WAJNMAN, S. Tendências de coorte nos diferenciais de rendimentos por sexo. In: HENRIQUES, R. (org.). Desigualdade e pobreza no Brasil. Rio de Janeiro: Ipea, 2000. p. $251-270$

LIMA, C. F. de et al. Diferenciais de rendimentos entre o migrante e o não migrante na região do Matopiba. Rio de Janeiro: Ipea, 2019. (Texto para Discussão, 2498). 
LIMA, R. M. N.; TEIXEIRA, E. C. Novos cenários para velhos trajetos: o nordestino sofre discriminação salarial na região Sudeste do Brasil? Revista Brasileira de Estudos Regionais e Urbanos, v. 14, n. 1, p. 131-154, 2020.

LONG, J. E. The effecton americanization on earnings: some evidence for women. Journal of Political Economy, v. 88, n. 3, p. 620-629, 1980.

LOUREIRO, V. B. et al. Diferencial de rendimentos dos imigrantes brasileiros de acordo com sua origem: um estudo dos fluxos migratórios para as regiões Sudeste, Norte e Centro-Oeste. Dissertação (Mestrado em Economia) - Universidade Federal de Viçosa (UFV), Viçosa, MG, 2018.

MADALOZZO, R. Occupational segregation and the gender wage gap in Brazil: an empirical analysis. Economia Aplicada, v. 14, n. 2, p. 147-168, 2010.

MINCER, J. Family migration decisions. Journal of Political Economy, v. 86, n. 5, p. 749-773, 1978.

NEVES, A. S. A. das et al. Mulheres imigrantes em Portugal: uma análise de gênero. Estudos de Psicologia (Campinas), v. 33, n. 4, p. 723-733, 2016.

NICODEMO, C.; RAMOS, R. Wage differentials between native and immigrant women in Spain: accounting for differences in support. International Journal of Manpower, v. 33, n. 1, p. 118-136, 2012.

ÑOPO, H. Matching as a tool to decompose wage gaps. The Review of Economics and Statistics, v. 90, n. 2, p. 290-299, 2008.

NORONHA, C. A.; VILELA, E.; CAMPOS, M. “Quem leva a pior?” Nordestinos e bolivianos no mercado de trabalho paulista. Revista Brasileira de Estudos de População, v. 36, 2019.

OJIMA, R.; NASCIMENTO, T. C. L. Nos caminhos para o Nordeste: reflexões sobre os impactos diretos e indiretos da migração de retorno no período recente. Redes: Revista do Desenvolvimento Regional, v. 20, n. 3, p. 48-62, 2015.

OLIVEIRA, K. F.; JANNUZZI, P. M. Motivos para migração no Brasil e retorno ao Nordeste: padrões etários, por sexo e origem/destino. São Paulo em Perspectiva, v. 19, n. 4, p. 134-143, 2005.

PASCHOALINO, P. A. T.; PLASSA, W.; SANTOS, M. P. Discriminação de gênero no mercado de trabalho brasileiro: uma análise para o ano 2015. Revista Econômica do Nordeste, v. 48, n. 3 , p. 43-54, 2017.

PERES, R. G.; BAENINGER, R. Migração feminina: um debate teórico e metodológico no âmbito dos estudos de gênero. In: ENCONTRO NACIONAL DE ESTUDOS POPULACIONAIS, 18. Anais [...]. Águas de Lindóia, SP: Abep, 2012.

RAMALHO, H. M. de B.; QUEIROZ, V. dos S. Migração interestadual de retorno e autosseleção: evidências para o Brasil. Pesquisa e Planejamento Econômico, v. 41, n. 3, p. 369-396, 2011.

RAMALHO, H. M. B.; SILVEIRA NETO, R. M. Migração de retorno e escolha ocupacional no Brasil. In: ENCONTRO NACIONAL DA ASSOCIAÇÃO BRASILEIRA DE ESTUDOS REGIONAIS E URBANOS, 7. Anais [...]. São Paulo: Aber, 2009.

RODRIGUES, K. C. T. T. et al. Diferença salarial segundo a condição de migração e sexo na Bahia. Revista Economia e Desenvolvimento, v. 14, n. 2, p. 181-195, 2015.

SASAKI, E. M.; ASSIS, G. O. Teorias das migrações internacionais. In: ENCONTRO NACIONAL DE ESTUDOS POPULACIONAIS, 12. Anais [...]. Caxambu: Abep, 2000.

SCHMIDT FILHO, R.; DO MONTE, P. A.; MICELI, M. Um estudo comparativo das disparidades salariais entre os migrantes nordestinos e os nativos paulistas no mercado de trabalho de São Paulo. Revista de Economia, v. 35, n. 1, p. 31-52, 2009. 
SHAMSUDDIN, A. F. M. The double-negative effect on the earnings of foreign-born females in Canada. Applied Economics, v. 30, n. 9, p. 1187-1201, 1998.

SIQUEIRA, L. B. O. Uma análise do fluxo migratório brasileiro: migração para regiões pobres e migração de retorno. Tese (Doutorado) - Universidade Federal de Pernambuco (UFP), Recife, 2006. Disponivel em: https://repositorio.ufpe.br/handle/123456789/3957.

VILELA, E. M. Desigualdade e discriminação de imigrantes internacionais no mercado de trabalho brasileiro. Dados, v. 54, n. 1, p. 89-128, 2011.

\title{
Sobre os autores
}

Maria Adreciana Silva de Aguiar é doutora e mestre pelo Programa de Pós-Graduação em Economia da Universidade Federal do Ceará (Caen/UFC) e graduada em Finanças pela Universidade Federal do Ceará (UFC).

João Mário Santos de França é professor associado do Departamento de Economia Aplicada da Universidade Federal do Ceará (UFC) e do Programa de Pós-Graduação em Economia (Caen/ UFC). Diretor do Instituto de Pesquisa e Estratégia Econômica do Ceará (Ipece).

\section{Endereço para correspondência}

\section{Maria Adreciana Silva de Aguiar}

Av. da Universidade, 2762, Prédio Caen, $1^{\circ}$ e $2^{\circ}$ andares, Benfica 60020-181 - Fortaleza-CE, Brasil

João Mário Santos de França

Av. da Universidade, 2762, Prédio Caen, $1^{\circ}$ e $2^{\circ}$ andares, Benfica 60020-181 - Fortaleza-CE, Brasil

\begin{abstract}
Is there a double negative effect on the wages of migrant women in Brazilian regions? A nonparametric approach
\end{abstract}

This article seeks to verify the existence of a double negative effect on the wages of migrant women (non-natural and return) in Brazilian regions. To capture the wage differential, Ñopo's (2008) non-parametric method was applied to data obtained from the 2005 and 2015 PNADs. The results showed that only non-natural migrant women in the Southeast region suffer from double disadvantage in the employment market. The first wage inequality concerns gender issues and also occurs in other Brazilian regions. The second difference in salary is due to the condition of non-natural migrants from the Southeast region. For other regions, migrant women (non-natural and return) have a salary advantage over non-migrant women.

Keywords: Women migrants. Wage disadvantage. Nopo decomposition. 


\section{Resumen}

¿Hay un doble efecto negativo en los salarios de las mujeres migrantes en las regiones brasileñas? Un enfoque no paramétrico

Este artículo busca verificar si existe un doble efecto negativo en los salarios de las mujeres migrantes (no naturales y de retorno) en las regiones brasileñas. Para capturar la brecha salarial, se utilizó el método no paramétrico Ñopo (2008) aplicado a los datos obtenidos de las encuestas nacionales por muestra de domicilios (PNAD) de 2005 y de 2015. Los resultados mostraron que solo las mujeres migrantes no naturales sufren doble desventaja en el mercado de trabajo en el sudeste. La primera desigualdad salarial se refiere al tema de género y también ocurre en otras regiones brasileñas. La segunda diferencia en el salario se debe a la condición de los migrantes no naturales de la región sudeste. Para otras regiones, las mujeres migrantes (no naturales y de retorno) tienen una ventaja salarial sobre las mujeres no migrantes.

Palabras clave: Mujeres migrantes. Desventaja salarial. La descomposición Ñopo.

Recebido para publicação em 01/02/2020

Aceito para publicação em 12/04/2021 


\section{Anexo}

\begin{tabular}{|c|c|}
\hline \multicolumn{2}{|r|}{ Descrição das variáveis } \\
\hline \multicolumn{2}{|c|}{ Variável dependente } \\
\hline $\operatorname{Ln}(\mathrm{W} / \mathrm{h})$ & Logaritmo natural do rendimento do trabalho principal por horas trabalhadas \\
\hline \multicolumn{2}{|c|}{ Atributos pessoais } \\
\hline Branco & $\begin{array}{l}\text { Variável dummy que assume valor } 1 \text { para branco e } 0 \text { não branco (preta, amarela, parda e } \\
\text { indígena) }\end{array}$ \\
\hline $\begin{array}{l}\text { Idade } 15 \text { a } \\
24 \text { anos }\end{array}$ & $\begin{array}{l}\text { Variável dummy: assume valor } 1 \text { para indivíduos com idade entre } 15 \text { e } 24 \text { anos e } 0 \text { caso } \\
\text { contrário }\end{array}$ \\
\hline $\begin{array}{l}\text { Idade } 25 \text { a } \\
34 \text { anos }\end{array}$ & $\begin{array}{l}\text { Variável dummy: assume valor } 1 \text { para indivíduos com idade entre } 25 \text { e } 34 \text { anos e } 0 \text { caso } \\
\text { contrário }\end{array}$ \\
\hline $\begin{array}{l}\text { Idade } 35 \text { a } \\
44 \text { anos }\end{array}$ & $\begin{array}{l}\text { Variável dummy: assume valor } 1 \text { para indivíduos com idade entre } 35 \text { e } 44 \text { anos e } 0 \text { caso } \\
\text { contrário }\end{array}$ \\
\hline $\begin{array}{l}\text { Idade } 45 \text { a } \\
54 \text { anos }\end{array}$ & $\begin{array}{l}\text { Variável dummy: assume valor } 1 \text { para indivíduos com idade entre } 45 \text { e } 54 \text { anos e } 0 \text { caso } \\
\text { contrário }\end{array}$ \\
\hline $\begin{array}{l}\text { Idade } 55 \text { a } \\
65 \text { anos }\end{array}$ & $\begin{array}{l}\text { Variável dummy: assume valor } 1 \text { para indivíduos com idade entre } 55 \text { e } 65 \text { anos e } 0 \text { caso } \\
\text { contrário }\end{array}$ \\
\hline $\begin{array}{l}\text { Estudo menos } \\
\text { de } 1 \text { ano }\end{array}$ & $\begin{array}{l}\text { Variável dummy que assume valor } 1 \text { para os que não possuem instrução ou têm menos de } 1 \\
\text { ano de estudo e } 0 \text { caso contrário }\end{array}$ \\
\hline $\begin{array}{l}\text { Estudo1 a } \\
4 \text { anos }\end{array}$ & $\begin{array}{l}\text { Variável dummy que assume valor } 1 \text { para os que possuem de } 1 \text { a } 4 \text { anos de estudo e } 0 \text { caso } \\
\text { contrário }\end{array}$ \\
\hline $\begin{array}{l}\text { Estudo } 5 \text { a } \\
10 \text { anos }\end{array}$ & $\begin{array}{l}\text { Variável dummy que assume valor } 1 \text { para os que possuem de } 5 \text { a } 10 \text { anos de estudo e } 0 \text { caso } \\
\text { contrário }\end{array}$ \\
\hline $\begin{array}{l}\text { Estudo } 11 \text { a } \\
15 \text { anos }\end{array}$ & $\begin{array}{l}\text { Variável dummy que assume valor } 1 \text { para os que possuem de } 11 \text { a } 14 \text { anos de estudo e } 0 \text { caso } \\
\text { contrário }\end{array}$ \\
\hline $\begin{array}{l}\text { Estudo mais } \\
\text { de } 15 \text { anos }\end{array}$ & $\begin{array}{l}\text { Variável dummy que assume valor } 1 \text { para os que possuem } 15 \text { ou mais anos de estudo e } 0 \text { caso } \\
\text { contrário }\end{array}$ \\
\hline \multicolumn{2}{|l|}{ Família } \\
\hline Casal & $\begin{array}{l}\text { Variável dummy que expressa o tipo de família. Assume valor } 1 \text { para os casais e } 0 \text { caso } \\
\text { contrário. }\end{array}$ \\
\hline Filho (5 anos) & $\begin{array}{l}\text { Variável dummy que assume valor } 1 \text { se a mulher possui algum filho menor que } 5 \text { anos de idade } \\
\text { e } 0 \text { caso contrário }\end{array}$ \\
\hline
\end{tabular}

\section{Mercado de trabalho} Dirigentes em Variável dummy que assume o valor 1 para dirigentes em geral e 0 caso contrário
geral

Ciências e artes Variável dummy que assume o valor 1 para profissionais das ciências e das artes e 0 caso

Técnicos de nível médio Variável dummy que assume o valor 1 para técnicos de nível médio e 0 caso contrário Serviços Variável dummy que assume o valor 1 para trabalhadores de serviços administrativos e 0 caso administrativos contrário

Serviços Variável dummy que assume o valor 1 para trabalhadores dos serviços e 0 caso contrário

Vendedores Variável dummy que assume o valor 1 para vendedores e prestadores de serviço do comércio e e serviço do 0 caso contrário

Agrícola Variável dummy que assume o valor 1 para trabalhadores agrícolas e 0 caso contrário

Produção, reparação e manutenção

Forças Armadas Variável dummy que assume o valor 1 para membros das Forças Armadas e auxiliares e 0 caso

Ocupações Variável dummy que assume o valor 1 para ocupações maldefinidas ou não declaradas e 0 maldefinidas caso contrário 
(Continuação)

\begin{tabular}{|c|c|}
\hline \multicolumn{2}{|r|}{ Descrição das variáveis } \\
\hline \multicolumn{2}{|l|}{ Residência } \\
\hline Norte & Variável dummy que assume valor 1 para residentes na região Norte e 0 caso contrário \\
\hline Nordeste & Variável dummy que assume valor 1 para residentes na região Nordeste e 0 caso contrário \\
\hline Sudeste & Variável dummy que assume valor 1 para residentes na região Sudeste e 0 caso contrário \\
\hline Sul & Variável dummy que assume valor 1 para residentes na região Sul e 0 caso contrário \\
\hline Centro-Oeste & Variável dummy que assume valor 1 para residentes na região Centro-Oeste e 0 caso contrário \\
\hline $\begin{array}{l}\text { Região } \\
\text { metropolitana }\end{array}$ & $\begin{array}{l}\text { Variável dummy que assume valor } 1 \text { para residentes em áreas metropolitanas e } 0 \text { caso } \\
\text { contrário }\end{array}$ \\
\hline Urbana & Variável dummy que assume valor 1 para residentes na zona urbana e 0 caso contrário \\
\hline \multicolumn{2}{|c|}{ Tempo de residência (migração) } \\
\hline Até 4 anos & $\begin{array}{l}\text { Variável dummy que assume valor } 1 \text { para aqueles com tempo de residência na unidade da } \\
\text { federação de até } 4 \text { anos e } 0 \text { caso contrário }\end{array}$ \\
\hline 5 a 9 anos & $\begin{array}{l}\text { Variável dummy que assume valor } 1 \text { para aqueles com tempo de residência na unidade da } \\
\text { Federação de } 5 \text { a } 9 \text { anos e } 0 \text { caso contrário }\end{array}$ \\
\hline $\begin{array}{l}10 \text { anos ou } \\
\text { mais }\end{array}$ & $\begin{array}{l}\text { Variável dummy que assume valor } 1 \text { para aqueles com tempo de residência na unidade da } \\
\text { federação de } 10 \text { anos ou mais e } 0 \text { caso contrário }\end{array}$ \\
\hline
\end{tabular}

Fonte: IBGE. Pesquisa Nacional por Amostra de Domicílios (PNAD) 2005 e 2015. Elaboração dos autores. 